extension. Psycholorical Review, 1962, 64, 221-227.

306-328.

FSTFS, W. K. The statistical approach to learning theory. In S. Koch (Ed.), Psychology: $A$ study of a science. Vol. 2. New York: McGraw-Hill, 1959. Pp. 380-491.

HULSF, S. H., JR., \& STANLEY, W. C. Extinction by omission of food as related to partial and secondary reinforcement. Journal of Experimental Psychology, 1956, 52,
WEINSTOCK, S. Resistance to extinction of a running response following partial reinforcement under widely spaced trials. Journal of Comparative \& Physiological Psychology, 1954, 47, 318-322.

WEINSTOCK, S. Acquisition and extinction of a partially reinforced running response at a 24-hour intertrial interval. Journal of Experimental Psychology, 1958, 56, 151-158.

\title{
Behavior of electric fish (Gymnotus carapo) in a group membership experiment*
}

\author{
HILARY O. BOX and G. W. MAX WESTBY \\ The University of Reading, Whiteknights, Reading, England
}

Four specimens of the electric fish, Gymnotus carapo, were used in an experiment to investigate the social interactions of members of this species. Four different two-member groups were established and observed for $20-\mathrm{min}$ sessions every day for 8 days. Two categories of aggressive behavior, approach and threat movements, were found to be inversely related to the phenomenon of "turning off" of electrical pulses. Further, the animal that became the more aggressive in any pairing could be predicted from the mean pulse frequency measured prior to the social experiment.

Many species of marine and freshwater fish produce electrical discharges. Recent experimental work has been concentrated on the river-living species of the two families Gymnotidae and Mormyridae. These animals emit continuous electric pulses from specialized tail organs that have been shown to be used for object location. The resting trequency of emission of the pulses varies considerably among individuals and among species. approximately $2-1,000 \mathrm{~Hz}$ in the Gymnotidae and $1.6 \mathrm{~Hz}$ in the Mormyridae (Lissman, 1958). Other factors affecting pulse frequency are the individual's level of activity and the temperature of the water (Lissman, 1951). The neurophysiology of the electroreceptors and their relationship with the lateral line and central nervous system has been discussed at length by Lissman (1958, 1963) and Bennett (1967).

Moreover, studies by Lissman (1958), Lissman \& Machin (1958), and Machin \& Lissman (1960) have demonstrated the remarkable discriminative and orientation abilities of Gymnarchus niloticus (Mormyridae) and Gymnotus carapo (Gymnotidae) utilizing their electric senses.

*This work was carried out while G. W. Max Westby was in receipt of an S.R.C. studentship.
These findings have led a number of us to speculate as to whether or not the electric signals of these animals may be used in social communication (e.g., Möhres, 1957; Lissman, 1958; Sebeok, 1965; Marler \& Hamilton, 1966). Further, there is some neurophysiological evidence, at least in Staetogenes species, that either an imposed electric field or the discharge of another nearby fish can modify the peripheral nerve impulse discharge to pulses of the electric organ (Hagiwara \& Morita, 1963). These reports, in addition to the information that very little is known about the social behavior of the Gymnotidae and Mormyridae have prompted our own

Table 1

Mean Values Taken Over All Trials for Approach and Threat Movements, Mean Durations of Electrical Silence and Mean Pulse Frequency for Each Individual

\begin{tabular}{cccccc}
\hline Group & Subject & Approaches & $\begin{array}{c}\text { Threat } \\
\text { Movements }\end{array}$ & $\begin{array}{c}\text { Electrical } \\
\text { "Turn-Offs" } \\
\text { (Seconds) }\end{array}$ & $\begin{array}{c}\text { Mean } \\
\text { Pulse } \\
\text { Frequency } \\
\text { (Hz) }\end{array}$ \\
\hline A + B & A & 15.50 & 0.20 & 14.0 & 67.12 \\
& B & 25.75 & 4.50 & 1.75 & 71.81 \\
C + D & C & 4.50 & 0.25 & 3.25 & 47.14 \\
& D & 15.75 & 0.10 & 1.50 & 65.68 \\
B + D & B & 21.0 & 4.25 & 3.0 & 71.81 \\
& D & 5.75 & 0.10 & 33.0 & 65.68 \\
A + C & A & 7.0 & 0.50 & 4.0 & 67.12 \\
\hline
\end{tabular}

investigations on the social modification of the continuous pulse emission in Gymnotus carapo. Independent unpublished work by Cleworth (1969) has also investigated some aspects of the social behavior of this species.

\section{METHOD}

Briefly, our experimental setup consisted of. a glass fiber tank measuring $120 \times 60 \times 60 \mathrm{~cm}^{3}$ filled to a depth of $15 \mathrm{~cm}$ with $100 \%$ conditioned tap water. A gravel bottom with several large stones was also provided. Recording electrodes were fitted into the end walls of the tank below the water level, and electrical activity of the fish was displayed on an oscilloscope.

All the animals were housed individually and maintained under constant temperature conditions $\left(24^{\circ} \pm 1^{\circ} \mathrm{C}\right)$ in a thermostatically controlled room which also housed the experimental tank. During the experiments the only illumination was from one 40-W red bulb suspended some $80 \mathrm{~cm}$ above the center of the tank. Again, before the trials began, each individual fish was observed in the experimental tank for 10 min per day for 4 days to obtain a measure of its general level of activity and the mean pulse frequency. Frequency readings were taken every minute during these $10-\mathrm{min}$ habituation trials, and these were used to compute an overall mean frequency for each individual.

We then went on to examine the general behavioral interactions and electrical activity of individual fish as members of different groups. The four animals used in this particular experiment were referred to as $\mathrm{A}, \mathrm{B}, \mathrm{C}$, and $\mathrm{D}$. These were combined together in such a way that the behavior of each could be examined when paired with two different individuals. Hence, the four groups set up were $\mathrm{AB}, \mathrm{CD}, \mathrm{BD}$, and $\mathrm{AC}$. Each of these groups was run for $20 \mathrm{~min}$ per day for 8 days, and all the groups were run in the same order throughout. The electrical activity of any two animals was continuously monitored throughout. A number of behavioral categories was also recorded. These had been determined from our previous experiments and observation 

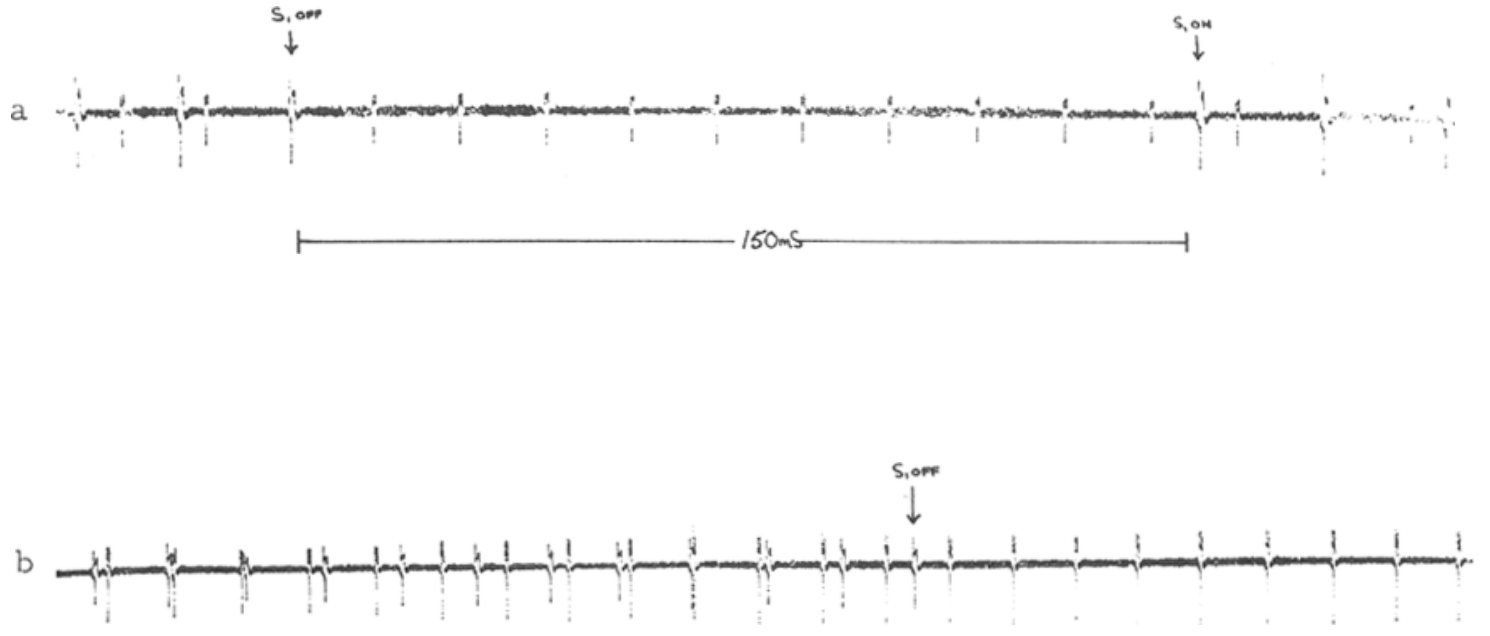

Fig. 1. An example of oscillograph records of the electrical activity of two Gymnotus carapo during an experimental session. Record a shows a period of $150 \mathrm{msec}$ during which one animal had "turned off" its pulses. Record b shows a similar "turn-off" $2 \mathrm{sec}$ later.

periods. The first of these was a measure of approach, which simply referred to the swimming of one animal directly toward another and which was scored only when it resulted in bodily contact. The second was a composite measure of threat movements, which were head butting, chasing, and occasional biting. Moreover, the most notable feature of the electrical behavior of these animals in social groupings was the occurrence of periods of electrical silence which varied from approximately $100 \mathrm{msec}$ to several seconds at a time. Figure 1 gives an example of "turning-off" behavior by one animal in the presence of another.

Table 1 shows the mean number of approaches and threat movements and the mean duration of "turn off" per animal in each group over the eight consecutive observation periods. It also shows the mean pulse frequency for each individual previously determined in the habituation trials.

\section{DISCUSSION}

Table 1 shows the essential results of this preliminary study. Mean scores for approach and threat movements are presented for each animal in each of the groupings. The table also gives the mean time spent "turned off" in each trial, together with the mean pulse frequencies recorded in the habituation trials. There are marked individual differences in mean pulse frequency that remain highly consistent over days (Kendall's $W=0.92$, $\mathrm{p}<.001)$.

A number of interesting points emerge from this data. The first is that the time each animal spent in electrical silence was inversely proportional to the number of approaches made by the animal. Moreover, the time spent "turned off" and the number of approaches varied considerably, depending on the way in which that $S$ was paired. For instance, S D spent an average of $33 \mathrm{sec}$ "turned off" when paired with B, but only $1.5 \mathrm{sec}$ when paired with $\mathrm{C}$.

Second, in each group one animal was consistently more aggressive than the other, i.e., it displayed more approaches and threat movements, whereas the other animal displayed less aggressive behavior and spent much more time electrically silent.

Third, that there were social interactions between individual fish was indicated by their behavior as members of different groups. Hence, A "turned off" more than $\mathrm{C}$ in the AC group, but C "turned off" more than $\mathrm{D}$ in the $\mathrm{CD}$ group, and $\mathrm{D}$ "turned off" more than B in the BD group. A similar relationship holds for the approach measure, but not so well for measures of threat. These results give an almost linear hierarchy for aggressive behavior in these Ss.

Finally, there appeared to be a relationship between the electrical characteristics of an individual fish and the probability of its becoming the more aggressive member of a group. There was a highly consistent inverse relationship between the time spent "turned off" and mean pulse frequency as measured before the animals were used in the social experiment. This indicated that the outcome of a given pairing could be predicted from individual measurements of pulse frequency. This finding has been subsequently confirmed by one of our more recent experiments in which there were a larger number of animals.

We have now started an extensive series of experiments to investigate the social modification of electrical signals. For example, we intend to synchronize film records of behavioral interactions with oscillographic recordings. Clearly, if we are to describe social behaviors in these animals, we must specify the components of the interaction sequences, as well as detailed analyses of eleotrical characteristics. We are also planning to investigate interspecies recognition by electrical communication systems.

\section{REFERENCES}

BENNETT, M. V. L. Mechanisms of clectrorecep:ion. In P. Cahn (Ed.), Lateral line detectors. Bloomington: University of Indiana Press, 1967. Pp. 313-393.

CLEWORTH, P. A. The tole of electrical discharges in the non-reproductive social behavior of Gymnotus carapo. Unpublished doctoral thesis, University of California at Los Angeles, 1969.

HAGIWARA, S., \& MORITA, H. Coding mechanisms of electroreceptor fibers in some electric fish. Journal of Neurophysiology, $1963,26,551-567$.

LISSMAN, H. W. Continuous electric signals from the tail of a fish, Gymnarchus niloticus. Nature, 1951, 167, 201-202.

LISSMAN, H. W. On the function and cvolution of electric organs in fish. Journal of Experimental Biology, 1958, 35, 156-191.

LISSMAN, H. W. Electric location by fishes. Scientific American, 1963, 208, 50-59.

LISSMAN, H. W., \& MACHIN, K. F. The mechanisms of object location in Gymnarchus niloticus and similar fish. Journal of Experimental Biology, 1958, 35, 451-486.

MACHIN, K. E., \& LISSMAN, H. W. The mode of operation of the electric receptors in Gymnarchus niloticus. Journal of Experimental Biology, 1960, 37, 801-811.

MARLER, P., \& HAMILTON, W. J. Mechanisms of animal hehavior. New York: Wiley, 1966.

MOHRES, F. Z. Elektrische Entladungen im Dienste der P. Revierabgrenzung bei lischen. Naturwissenschaften, 1957, 44, 431-432.

SEBEOK, T. A. Animal communication. Science, 1965, 147, 1006-1014. 